\title{
New Korean record and redescription of Dienerella (Dienerella) costulata (Reitter) (Coleoptera: Latridiidae: Latridiinae)
}

\author{
Sun-Jae Park* \\ Animal Resources Division, National Institute of Biological Resources, Incheon 404-708, Korea \\ *Correspondent: sun1763@korea.kr
}

\begin{abstract}
The genus Dienerella Reitter and its described species are reported for the first time in Korea. Scanning Electronic Microscope (SEM) photographs of habitus and diagnostic characters, and line drawings of male genetalia are presented. All specimens of the species were collected from inside of a building associated with dried collections, but no evidence is available of the damage caused by the species.
\end{abstract}

Keywords: Coleoptera, Dienerella (Dienerella) costulata, Korea, Latridiidae, taxonomy

(C) 2013 National Institute of Biological Resources

DOI: 10.12651/JSR.2013.2.2.185

\section{INTRODUCTION}

The latridiine genus Dienerella Reitter, containing 39 species in two subgenera (Dienerella Reitter and Cartoderema Reitter), is worldwide especially 26 species in Palaearctic region (Johnson, 2007; Rucker, 2010). In East Asia, eight, two and four species of Dienerella are listed from Japan, far eastern Russia and northeast China, respectively (Johnson, 2007).

The genus is characterized by having a very small, elongate and somewhat depressed body, head well produced in front of eyes, eyes close to rear margin of head, and pronotum without longitudinal ridges. Most members of the genus are found in association with stored grains, drug stores, wheat fields, wine cellars, museums and homes (Bousquet, 1990; Majka et al., 2009). They usually feed on the hyphae and spores of filamentous fungi, and the spores of slime mold. Some species are known to be potential pests in air-conditioning and refrigeration systems, or as hygienic pests and contaminators of brewer's yeast tablets (Hinton, 1945; Lawrence and Newton, 1980; Böcher, 1988; Carlton, 1988; Bousquet, 1990; Stejskai, 1995).

At present, eight species of the family Latridiidae were known from Korea (Kim et al., 1994; Johnson, 2007) and the genus and species Dienerella (Dienerella) costulata (Reitter) are reported for the first time in Korea. A redescription, SEM photographs of habitus and diagnostic characters, and line drawings of male genetalia are presented.

\section{Materials and Methods}

\section{Materials examined}

In this study, 36 specimens were examined. All materials used in the study were collected manually from inside a building associated with dried plant or insect collections and were subsequently deposited in the National Institute of Biological Resources (NIBR, Incheon).

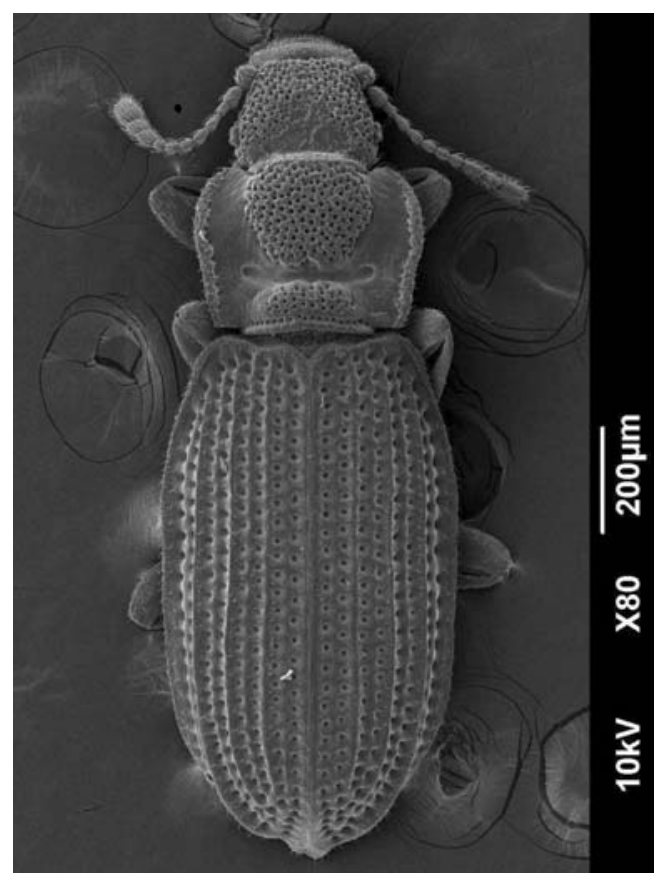

Fig. 1. Habitus of Dienerella costulata. 

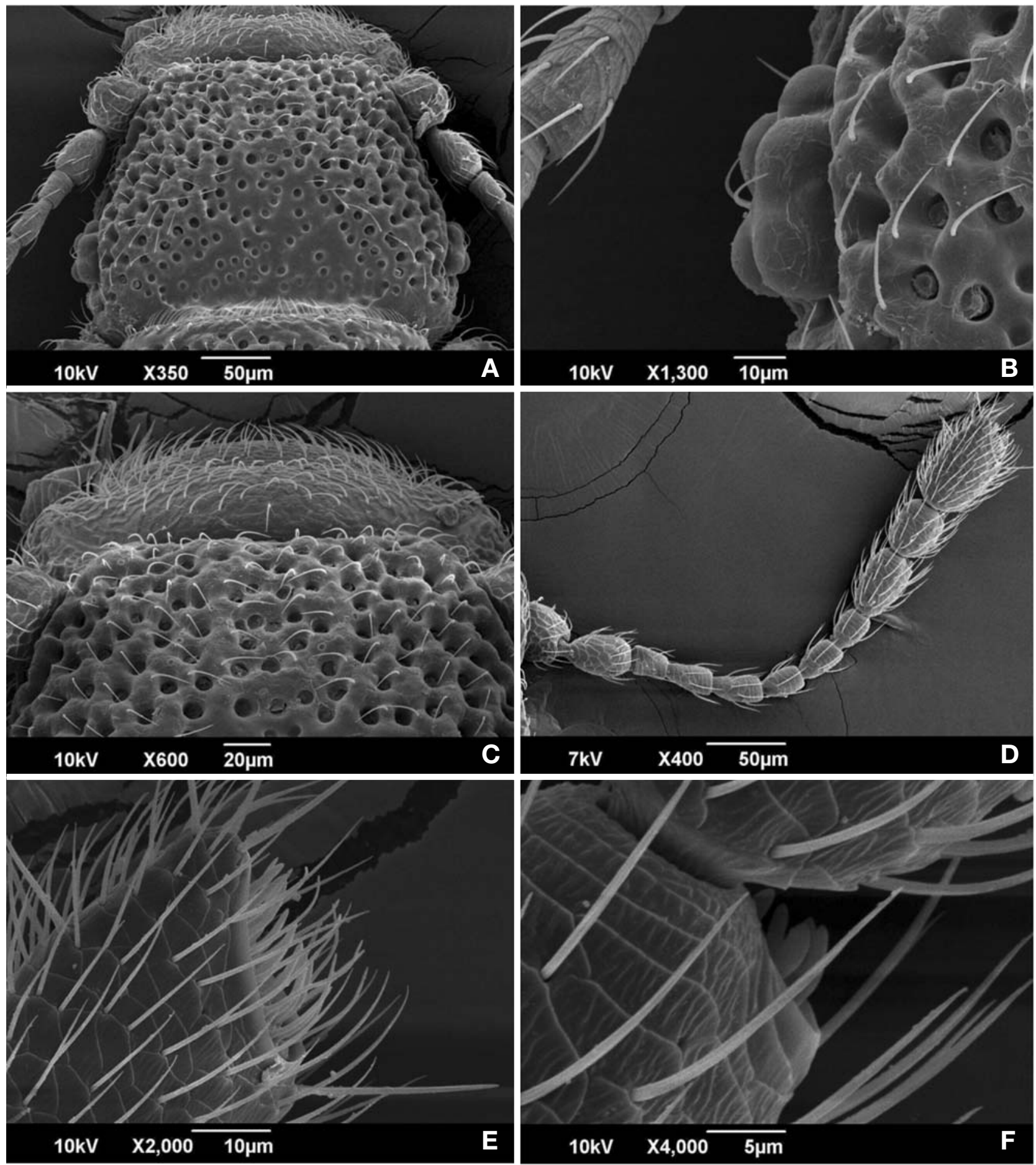

Fig. 2. Dienerella costulata. A. head, dorsal aspect. B. compound eye, dorsal aspect. C. frons and clypeus, dorsal aspect. D. antenna, dorsal aspect. E. apical end of antennomere 11. F. apical end of antennomere 9.

\section{Slide preparations}

For some characters, it was necessary or advantageous to make permanent, full-body preparations on glass micro- scope slides. In this work, the methods of Hanley and Ashe (2003) were used for the slide preparations. The mounting medium Euparal was used for these specimen preparations. 

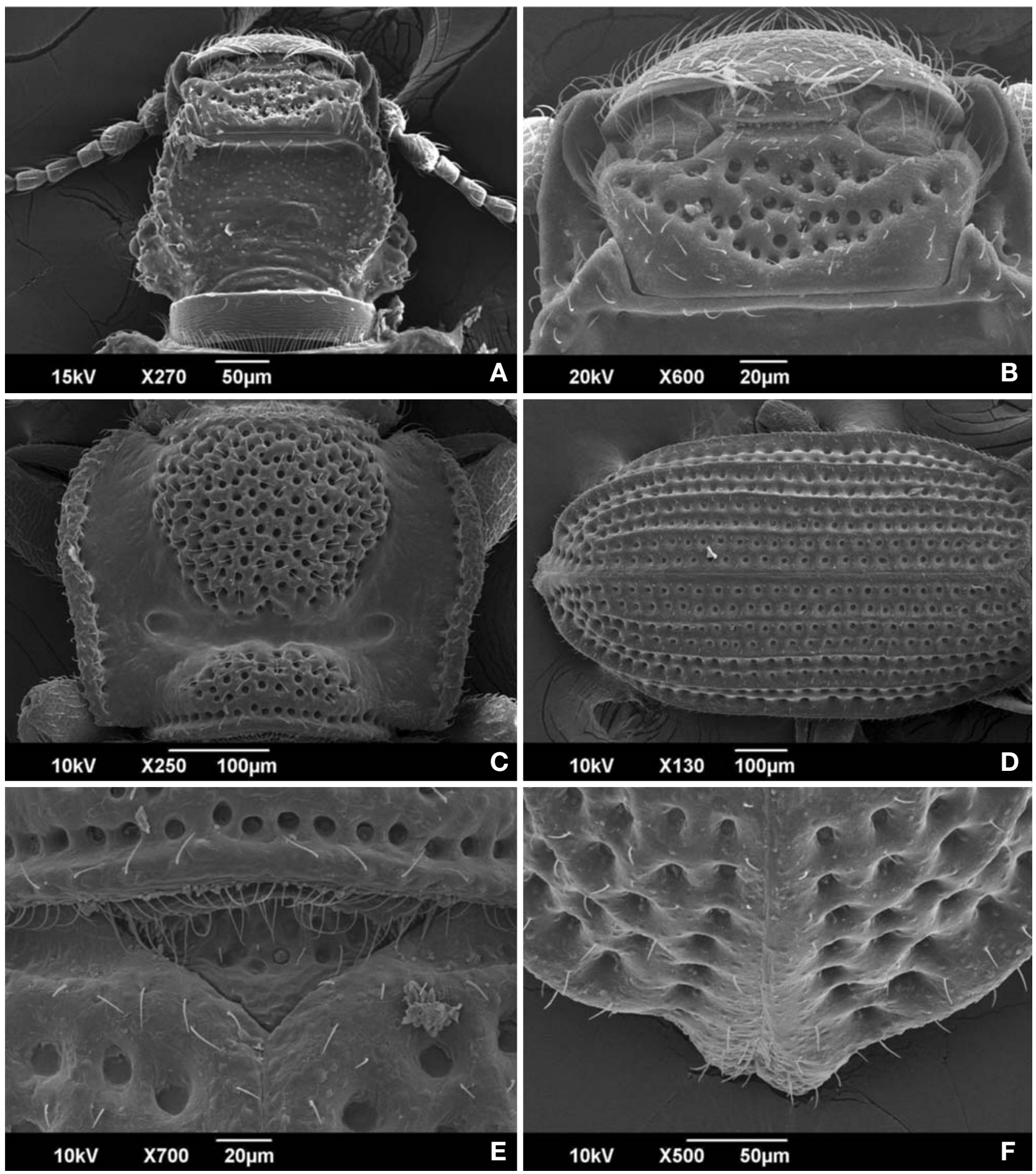

Fig. 3. Dienerella costulata. A. head, ventral aspect. B. mouthparts, ventral aspect. C. pronotum, dorsal aspect. D. elytra, dorsal aspect. E. scutellum, dorsal aspect. F. posterior end of elytra, dorsal aspect.

\section{Scanning electron microscopy (SEM)}

Dried specimens were sputter coated with gold (Sputter Coater: Cressington 108 Auto) and examined and photographed using SEM (JEOL: JSM-6390LV).

\section{Drawings of structural details}

All 'aedeagus' drawings were made using an Olympus BX-51 compound microscope with a drawing tube. 

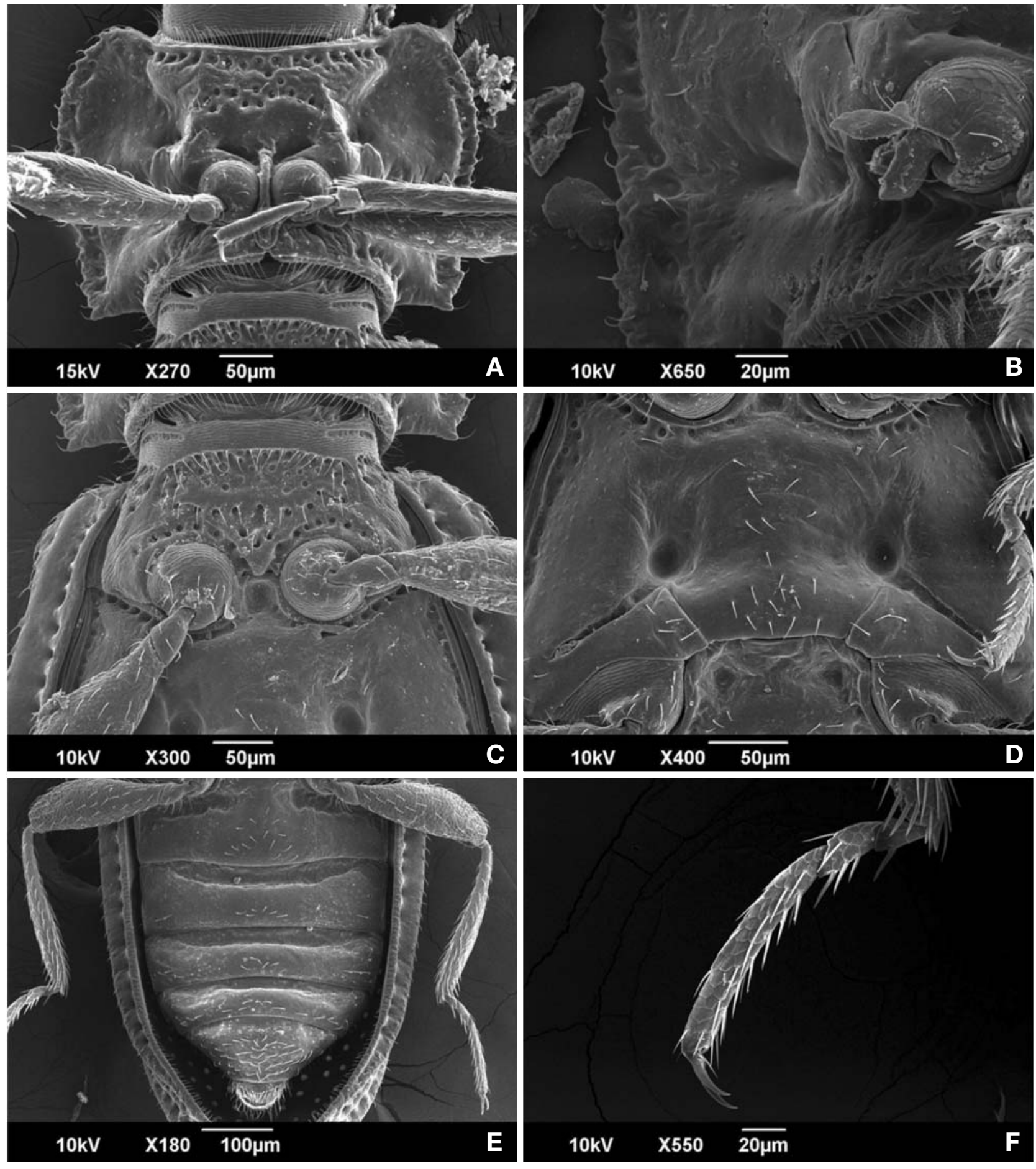

Fig. 4. Dienerella costulata. A. prosternum, ventral aspect. B. prohypomeron, ventral aspect. C. mesosternum, ventral aspect. D. metasternum, ventral aspect. E. abdomen, ventral aspect. F. tarsi of metaleg.

\section{RESULTS AND Discussion}

Genus Dienerella Reitter, 1911 (Korean name: Gombo-seop-beol-re-sok)
Subgenus Dienerella Reitter, 1911 (Korean name: Gom-bo-seop-beol-re-a-sok)

Type species: Latridius elegans Aubé, 1850.

Dienerella (Dienerella) costulata (Reitter) (Korean name: 


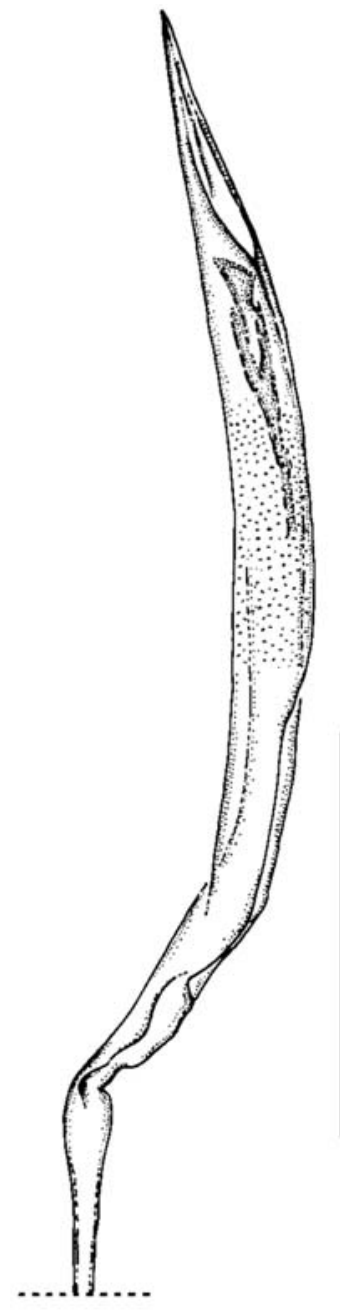

5

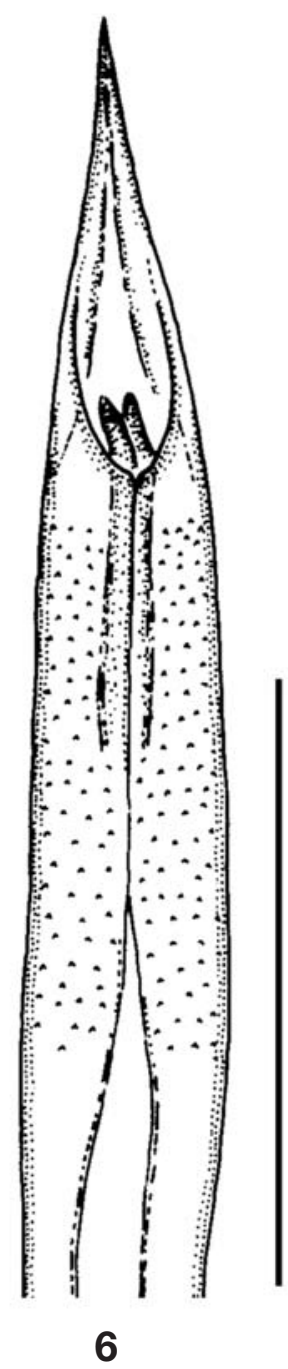

Figs. 5, 6. Aedeagus of Dienerella costulata. 5. lateral aspect. 6 . dorsal aspect. Scales $=0.1 \mathrm{~mm}$.

Gom-bo-seop-beol-re) (Figs. 1-6)

Cartodere costulata Reitter, 1877: 114.

Dienerella costulata: Bousquet, 1990: 131; Majka et al., 2009: 326.

Description. Length 1.3-1.6 mm. Body (Fig. 1) elongate, parallel, dorsoventrally depressed, strongly punctate, widest at anterior one-third of elytra. Color brown to dark brown.

Head. Slightly wider than long, strongly punctate apically and weakly punctate basally in dorsal aspect (Fig. 2A); clypeus impunctate (Fig. 2C); antennae with 11 antennomeres, apical three antennomeres clubbed and with sensilla apically (Fig. 2D-F); eyes weakly developed, with 4 or 5 facets (Fig. 2B); gular region impunctate, minute projections scattered sparsely, setae absent, weakly emarginated (Fig. 3A); mentum strongly punc- tate; labrum with loosely covered mouthparts (Fig. 3B).

Pronotum (Fig. 3C). Slightly wider than long, trapezoid, widest at anterior one-third, weakly narrowed posteriorly; lateral margins well marginate; large deep depressions along lateral margins smooth; two small round pits present on depressions; a deep transverse groove present at posterior one-third and connecting pits; mesal-anterior and mesal-posterior areas divided by transverse, strongly punctate groove.

Elytra. Sides evenly rounded; without broad, shallow depressions dorsally and laterally; with eight puncture striae; interstriae 3, 5, and 7 carinate; interstria 3 vaguely carinate, not complete, straight from base to middle, weakly rounded posteriorly; interstria 5 carinate, not complete, straight from base to middle, gently rounded in posterior one-third; interstria 7 clearly carinate, complete, extending from base to apex, straight from base to middle, posterior one-third gently rounded; striae 5, 6 complete, extending from base to apex (Fig. 3D); apex broadly pointed, asymmetrical (Fig. 3F); scutellum heartshaped but visible as weakly punctate triangle (Fig. 3E).

Prosternum. Procoxa slightly separated by prosternal process; impunctate except for mesal-anterior area; minute projections scattered sparsely; setae absent (Fig. 4A); two small deep pits present on prohypomeron (Fig. 4B).

Mesosternum (Fig. 4C). Mesocoxa moderately separated by mesosternal process; strongly punctate mesally and anteriorly, impunctate laterally.

Metasternum (Fig. 4D). Two deep round pits present mesally, with one small round pit between mesocoxa; with a short narrow groove reaching to each pit; minute projections scattered sparsely; metacoxae widely separated; impunctate except for along anterior and lateral margins; sparsely setose mesally and posteriorly.

Abdomen. With two small round pits on sternite I between metacoxae (Fig. 4D); sternite I with broad depressed groove behind pits expanding to lateral margins, sparsely setose mesally and anteriorly; sternites II-V with narrowly depressed areas anteriorly; sternites II-III sparsely setose mesally and laterally; sternites IV-V sparsely setose on non-depressed areas (Fig. 4E).

Legs (Fig. 4E, F). Slender; pro- and mesocoxae round, metacoxae oval; tarsi 3-3-3, all tarsomere 3 longer than 1-2 combined.

Aedeagus (Figs. 5, 6). Subparalled in dorsal aspect; gently tapered apically in dorsal aspect; apex acute; arcuate in lateral aspect.

Materials examined. $5 \Im^{7} \Im^{7}, 5$ 우 우, National Institute of Biological Resources, Gyeongseo-dong, Incheon, Korea, 7 VII 2011, S.-J. Park; 26 exs, same data as formers.

Distribution. Korea, Japan, Europe, North America.

Remarks. This species is similar to Dienerella filiformis (Gyllenhal), but can be distinguished from it by its 
very small eyes, each with only 4 or 5 facets, elytral interstriae 3,5 and 7 carinate, and elytral striae 5 and 6 complete, extending from base to apex (Fig. 3D). In contrast, $D$. filiformis has relatively larger eyes, elytral interstriae not carinate, and elytral striae 5 and 6 merge, forming a single stria posteriorly. It is found in grain stores, cellars, and drug stores, where it is associated with various dried products in storage (Hinton, 1945). All the specimens collected were from inside a building associated with dried plant or insect collections under conditions of regular temperature $\left(18-20^{\circ} \mathrm{C}\right)$ and humidity (under 55\%). However, there was no evidence of damage that might have been caused by this species.

\section{Acknowledgements}

I thank Mrs. Jung-Hyun An (National Institute of Biological Resources, Incheon) who helped with the SEM photographs.

\section{REFERENCES}

Aubé, C. 1850. Description de quelques insects coléoptères appurtenant à l'Europe et à l'Algérie. Annales de la Société Entomologique de France (2)8:299-346.

Böcher, J. 1988. The Coleoptera of Greenland. Meddelelser om Grønland, Bioscience 26:1-100.

Bousquet, Y. 1990. Beetles associated with stored products in Canada: an identification guide. Publication 1837 , Research Branch, Agriculture Canada, Ottawa, Ontario.

Carlton, C.E. 1988. Dienerella filum (Aubé) (Coleoptera: Lathridiidae), a potential pest of air conditioning systems. The Coleopterists Bulletin 42(3):263-264.

Hanley, R.S. and J.S. Ashe. 2003. Techniques for dissecting adult aleocharine beetles (Coleoptrea: Staphylinidae). Bulletin of Entomological Research 93:11-18.

Hinton, H.E. 1945. A monograph of the beetles associated with stored products. Vol. 1. British Museum (Natural History), London, England.

Johnson, C. 2007. Lathridiidae. In: I. Löbl and A. Smetana (eds.), Catalogue of Palaearctic Coleoptera. Volume 4. Elateroidea, Derodontoidea, Bostrichoidea, Lymexyloidea, Cleroidea, Cucujoidea, Apollo Books, Stenstrup. pp. 635-648.

Kim, J.I., Y.J. Kwon, J.C. Paik, S.M. Lee, S.L. Ahn, H.C. Park and H.Y. Chu. 1994. Check List of Insects from Korea. Kon-Kuk University Press, Seoul.

Lawrence, J.F. and A.F.Jr. Newton. 1980. Coleoptera associated with fruiting bodies of slime molds (Myxomycetes). The Coleopterists Bulletin 34(2):129-144.

Majka, C.G., D. Langor and W.H. Rücker. 2009. Lathridiidae (Coleoptera) of Atlantic Canada: new records, keys to identification, new synonyms, distribution, and zoogeography. The Canadian Entomologist 141:317-370.

Reitter, E. 1877. [new taxa]. In: J.A.A.H. Putzeys, J. Weise, G. Kraatz, E. Reitter and W. Eichhoff (eds.), Beiträge zur Käferfauna von Japan, meist auf R. Hiller's Sammlungen basirt (Erstes Stück), Deutsche Entomologische Zeitschrift. pp. 81-128.

Reitter, E. 1911. Fauna Germanica. Die Käfer des Deutschen Reiches. Nach der analytischen Methode bearbeitet. III. Band. Stuttgart: K. G. Lutz, 436 pp., pls 81-128.

Rucker, W.H. 2010. Checklist Latridiidae \& Merophysiinae of the World. ISSN 1868-2168.

Stejskai, V. 1995. The first record of a damage to tabletted brewer's yeast caused by Dienerella filum (Aubé) (Coleoptera, Lathridiidae). Anzeiger für Schädlingskunde 68(6): 128.

Submitted: April 9, 2013, Accepted: August 2, 2013 